\title{
BMJ Open Rounding of birth weights in a neonatal intensive care unit over 20 years: an analysis of a large cohort study
}

\author{
Anthony J Emmerson, ${ }^{1}$ Stephen A Roberts ${ }^{2}$
}

To cite: Emmerson AJ, Roberts SA. Rounding of birth weights in a neonatal intensive care unit over 20 years: an analysis of a large cohort study. BMJ Open 2013;3:e003650. doi:10.1136/bmjopen-2013003650

- Prepublication history for this paper is available online. To view these files please visit the journal online (http://dx.doi.org/10.1136/ bmjopen-2013-003650)

Received 24 July 2013 Revised 11 November 2013 Accepted 13 November 2013

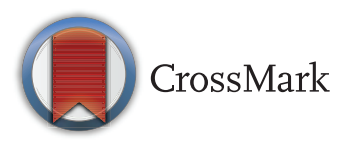

\footnotetext{
${ }^{1}$ Newborn Intensive Care Unit, St Mary's Hospital, Central Manchester University Hospitals NHS Foundation Trust, Manchester Academic Health Science Centre (MAHSC), Manchester, UK ${ }^{2}$ Centre for Biostatistics, Institute of Population Health, University of Manchester, Manchester Academic Health Science Centre (MAHSC), Manchester, UK
}

\section{Correspondence to} Dr Anthony J Emmerson; Anthony.emmerson@cmft. nhs.uk

\begin{abstract}
Objective: To determine the frequency of birth weight digit preference for infants admitted to a large neonatal intensive care unit (NICU), the scale of rounding and its dependence on birth weight, and time and the impact on prescribing accuracy.

Design: A consecutive cohort of birth weights extracted retrospectively from a single clinical database. Setting and participants: Birth weights from 9170 inborn infants recorded on an electronic prescribing database admitted to NICU over 20 years.
\end{abstract}

Statistical approach: Data are presented for the frequency of each of the possible pairs of final digits. A statistical model of digit preference assuming rounding is used to quantify the proportions rounding to specific accuracy levels. These proportions are compared between those $<1000 \mathrm{~g}$ and those above and over the 20-year time period.

Results: From a population of 9170 infants admitted over 20 years, there was a highly statistically significant digit bias with an increased prevalence of multiples of $100(p<0.0001), 50(p=0.007), 20(p<0.0001), 10$ $(p<0.0001), 5(p<0.0001)$ and $2(p=0.0005)$. There was clear evidence of a reduced $100 \mathrm{~g}$ digit bias for infants 500 and $1000 \mathrm{~g}(0 \%)$ compared with those between 1000 and $4500 \mathrm{~g}$ (3.7\%). The maximum birth weight error due to digit bias for all infants was $5 \%$. There was clear evidence of an improvement in accuracy over 20 years.

Conclusions: Digit bias in birth weights over 20 years in a tertiary NICU is highly significant at the 100,50 , 20, 10, 5 and 2-digit levels. There has been a substantial improvement in the accuracy of birth weight measurements over 20 years. The likely maximum error due to birth weight digit bias is $5 \%$ and is within an acceptable tolerance for drug dosing even at very low birth weights.

\section{INTRODUCTION}

Accurate birth weight measurements are essential for safe delivery of care to newborn preterm and term infants especially for prescriptions. Drug-related events in the hospital setting are the highest cause of recorded errors both in the $\mathrm{USA}^{1}$ and in the UK

\section{Strengths and limitations of this study}

- The strengths of this study include 9170 birth weight measurements from a single unit entered prospectively into a neonatal prescribing database.

- The impact on the degree of rounding of different birth weight groups and over time is identified.

- It is not possible to investigate the rationale for rounding and digit bias retrospectively.

National Health Service (NHS). ${ }^{2}$ The UK National Patient Safety report Safety in doses: medication safety incidents in the NHS $S^{2}$ reported on drug errors across all areas of medicine in 2007-2008 and showed that 28.7\% of reported drug errors in adult patient groups were due to the wrong dose, strength or frequency of medications.

There are a range of potential sources of drug errors including documentation, calculation, preparation and administration errors. ${ }^{3}{ }^{4}$ While in adult healthcare the dose administered may not be weight related, in neonatal intensive care almost all doses are prescribed based on the weight of the infant. Drugs are frequently prescribed shortly after birth with the birth weight used for calculation.

Drug errors in neonatal care are common with 3380 drug errors being reported to the UK National Patient Safety reporting and learning system between April 2008 and April 2009..$^{5}$ There were 507 neonatal drug errors due to gentamicin administration. While $96 \%$ were reported to cause no harm, there was concern that there may be underreporting as long-term renal impairment or hearing loss may not become evident until after discharge. Errors in birth weight measurement or recording may therefore lead to overtreatment or undertreatment.

Newborn infants admitted to a tertiary neonatal intensive care unit (NICU) range in birth weight widely from under 500 to 
over $4500 \mathrm{~g}$. Many infants require an early prescription for drugs and infusions, and the accuracy of the birth weight is critical for prevention of drug errors. Infants who weigh less than $1000 \mathrm{~g}$ at birth require particularly accurate weighing, and the scales used in the tertiary NICU weigh to the $1 \mathrm{~g}$ level. To increase the accuracy of the birth weights, nursing protocol requires deduction of the weight in grams of any item that was unable to be removed prior to the measurement of the birth weight such as an endotracheal tube inserted as part of resuscitation. The definitive birth weight recorded should therefore be at the $1 \mathrm{~g}$ level.

Infants with birth weights of less than $1000 \mathrm{~g}$ are at greater risk of drug errors as the impact from rounding or truncating effects is much greater and they are a particularly vulnerable group. Small birth weight rounding differences could potentially increase the adverse drug effects.

Digit bias and rounding have been identified in several areas of medicine ${ }^{6}$ including in the measurement of birth weights, ${ }^{7}$ and is a well-recognised phenomenon. One previous study involving birth weight registrations from the 1980 s included predominantly term infants weighed in a variety of institutions across Canada and recorded on a civil registration system. The potential for digit preference in this system by a number of individuals was increased.

It is unknown whether a similar digit preference with rounding or truncation of birth weights might occur for infants admitted to NICU where there is an expectation of accuracy of prescription and administration of drug and fluid medications. Over the past 20 years, there have been national and local drives for quality care with improved drug safety. It is unclear whether this has resulted in an identifiable behavioural change on the accuracy of weighing and whether there has been any alteration in the frequency of rounding or truncation of birth weight measurements.

Neonatal-specific computerised prescribing systems are used in order to minimise drug calculation and prescription errors, but these rely on accurate birth weight measurements for the calculation of the dosages of drugs and infusions. The accuracy of these systems would be reduced if the recorded birth weights were significantly altered by digit bias.

The study, therefore, sets out to answer whether birth weights from a single tertiary NICU showed evidence of digit bias and if so did this vary across different weight bands groups and over time. The impact on prescribed dose error of any identified digit bias was then explored.

\section{Methods}

All infants were weighed on admission to NICU within 60 min of birth using fully calibrated Weylux 850BT/BMI class III baby scales, H Fereday \& Sons, Harlow Essex, CM19 5QP, UK. These record a stable digital weight at a $1 \mathrm{~g}$ level but have a defined absolute accuracy of $\pm 5 \mathrm{~g}$. These scales, or their equivalent, have been used consistently over the past 20 years. The scales are regularly calibrated in line with the manufacturer's standards.

Birth weights for all infants between 500 and $4500 \mathrm{~g}$ admitted to NICU between June 1993 and May 2013 were extracted from an electronic patient database utilised predominantly for accurate prescribing of intravenous drugs and fluids. This system has been used for all prescriptions on NICU over the past 20 years. The electronic patient record database system was initiated in May 1993 specifically to minimise prescribing error risk. Infants born in other institutions and subsequently admitted were excluded.

A subset of infants $<1000 \mathrm{~g}$ was also analysed. During that time, 9170 inborn infants were admitted to the tertiary NICU and $100 \%$ of birth weights were extracted.

Data extracted from the database were analysed to determine the frequency of weight measurements at $1 \mathrm{~g}$ intervals from 500 to $4500 \mathrm{~g}$. Weights outside this range were excluded as the number of infants above and below this weight range was very small.

\section{Statistical analysis}

Birth weights were recorded with a $1 \mathrm{~g}$ resolution and the number of measurements with each of the possible 100 last two digits was determined and displayed graphically along with the observed/expected ratio based on a uniform distribution of digits. The significance of the peaks at multiples of 2, 5, 10, 20, 50 and 100 was determined using a Poisson regression model.

A statistical model was devised assuming that the underlying distribution of the last two digits was uniform with the number of each digit pair observed following a Poisson distribution. ${ }^{8}$ It was postulated that there were subsets of observations which were then rounded to the nearest $100,50,20,10,5$ or 2 which gives an expected distribution of digits as a function of the proportion rounded to each level of accuracy. The proportions, based on each behaviour, were fitted to the observed distribution by direct maximisation of the likelihood. Alternative models with more or fewer rounding points were tested by fitting the appropriate models and testing

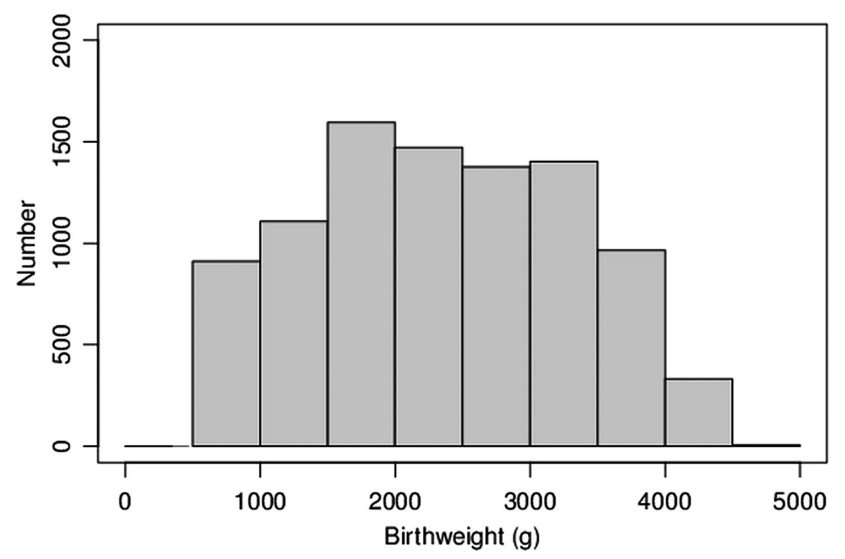

Figure 1 Number of infants by weight. 

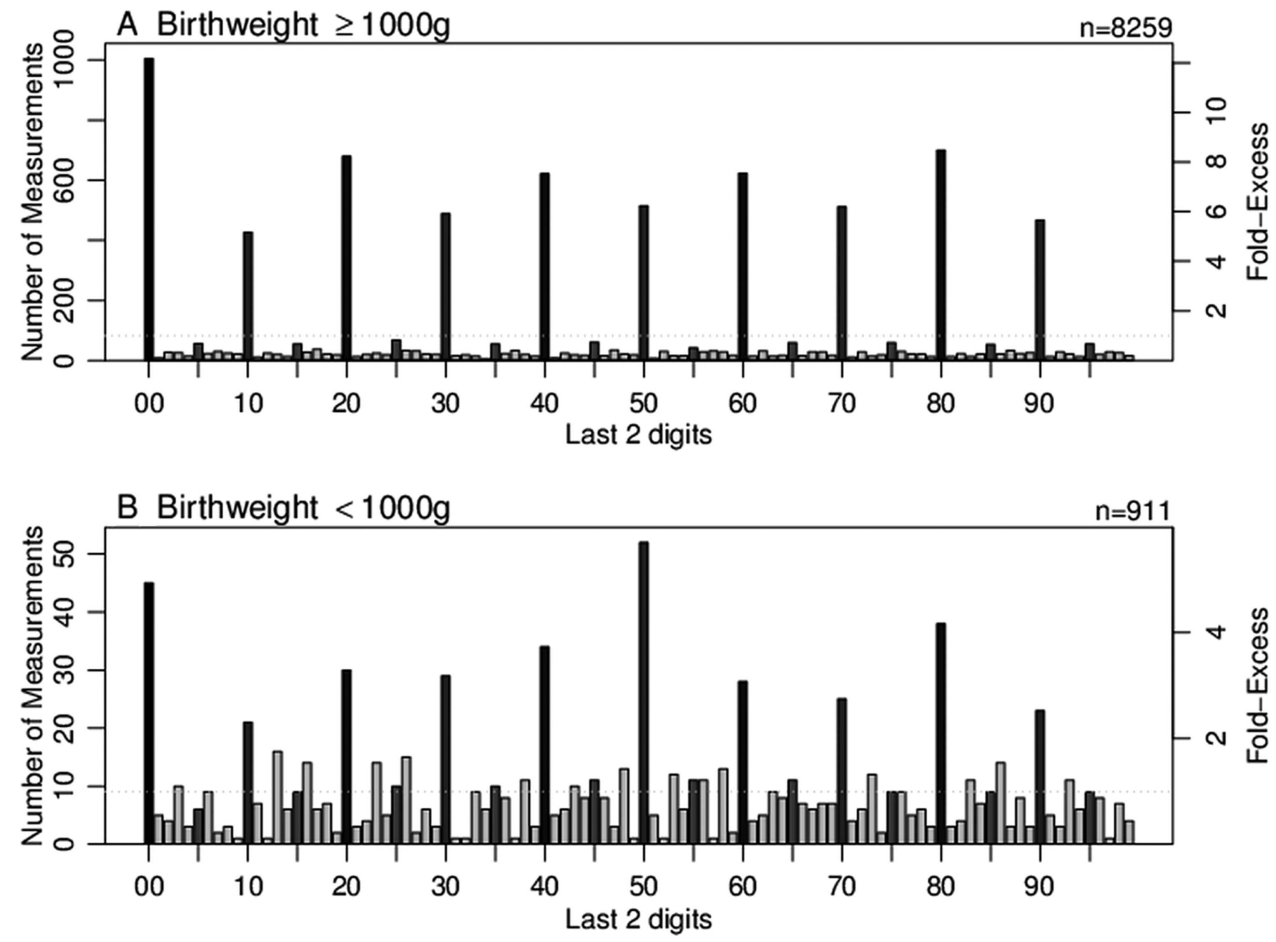

Figure 2 Distributions of recorded weight measurements for infants $<1000$ and $\geq 1000 \mathrm{~g}$. The horizontal lines show the expected number if digits were randomly distributed.

using likelihood ratio tests. The statistical significance of specific rounding points was similarly tested by fitting models excluding the single points.

\section{RESULTS}

There were 9170 inborn infants admitted over the 20 -year period. Of these $911(10 \%)$ were $<1000 \mathrm{~g}$ and are considered a particularly vulnerable group. The distribution of birth weights is shown in figure 1 .

The observed number in each of the digit bands between 0 and 99 is shown in figure 2 and shows a marked excess of 11.5 times that expected having both last digits zero, assuming all digits would have an equal likelihood of being measured. There was a striking excess of recorded birth weights at multiples of $10 \mathrm{~g}$ (fivefold to eightfold) with multiples of 20 and 50 being more common. Multiples of five are also more common than the remaining digits. The increased prevalence of multiples of 100 $(\mathrm{p}<0.0001), 50 \quad(\mathrm{p}=0.007), 20(\mathrm{p}<0.0001), 10(\mathrm{p}<0.0001)$, $5(\mathrm{p}<0.0001)$ and $2(\mathrm{p}=0.0005)$ is all highly significant.

Modelling the rounding for the whole dataset shows that $3.2 \%$ of the time there was rounding to the nearest $100 \mathrm{~g}$ and $46.7 \%$ to the nearest $10 \mathrm{~g}$ (table 1 ).

Analysis of infants $<1000 \mathrm{~g}$ shows that there is a greater degree of accuracy with no detectable rounding to $100 \mathrm{~g}$ level but $4.5 \%$ were rounded to $50 \mathrm{~g}$ and $15.7 \%$ to $10 \mathrm{~g}$. In total, $76.4 \%$ of the weights were accurate to the $5 \mathrm{~g}$ level compared with $33.9 \%$ for infants $\geq 1000 \mathrm{~g}$ birth weight (table 1 and figure 2).

In total, $4.5 \%$ of infants with birth weights between 500 and $999 \mathrm{~g}$ were recorded to $50 \mathrm{~g}$ accuracy which if we assume that this is due to rounding gives a maximum error of $5 \%$, and $3.7 \%$ of infants with birth weights between 1000 and $4500 \mathrm{~g}$ had rounding to $100 \mathrm{~g}$, giving a maximum percentage error of $5 \%$.

The accuracy of weighing has increased steadily over the 20-year period (figure 3); for the smallest babies $(<1000 \mathrm{~g})$ only $18 \%$ were recorded accurately (to $1 \mathrm{~g})$ in 1995, but this rose to $98 \%$ in 2013.

\section{DISCUSSION}

Neonatal intensive care requires accuracy over drug dosing as small errors can potentially lead to significant adverse effects especially as they are particularly vulnerable group with immature renal and hepatic function affecting drug handling. In view of the 10 -fold weight difference between the smallest and the largest newborn

Table 1 Modelled estimates of the degree of rounding, showing the proportions rounding to various digits

\begin{tabular}{llll}
$\begin{array}{l}\text { Rounding to } \\
\text { nearest... }\end{array}$ & $\begin{array}{l}\text { All data } \\
\text { Per cent } \\
\text { (SE) }\end{array}$ & $\begin{array}{l}\text { <1000 g } \\
\text { Per cent } \\
\text { (SE) }\end{array}$ & $\begin{array}{l}\text { 年000 g } \\
\text { Per cent } \\
\text { (SE) }\end{array}$ \\
\hline 100 & $3.2(0.5)$ & $0.0(1.1)$ & $3.7(0.5)$ \\
50 & $1.5(0.6)$ & $4.5(1.5)$ & $1.0(0.6)$ \\
20 & $10.4(0.9)$ & $3.3(2.1)$ & $11.1(1.0)$ \\
10 & $46.7(1.2)$ & $15.7(3.0)$ & $50.2(1.2)$ \\
5 & $8.9(0.6)$ & $9.0(2.3)$ & $8.8(0.6)$ \\
2 & $2.1(0.6)$ & $8.4(3.0)$ & $1.5(0.6)$ \\
1 & $27.2(-)$ & $59.0(-)$ & $23.6(-)$ \\
\hline
\end{tabular}




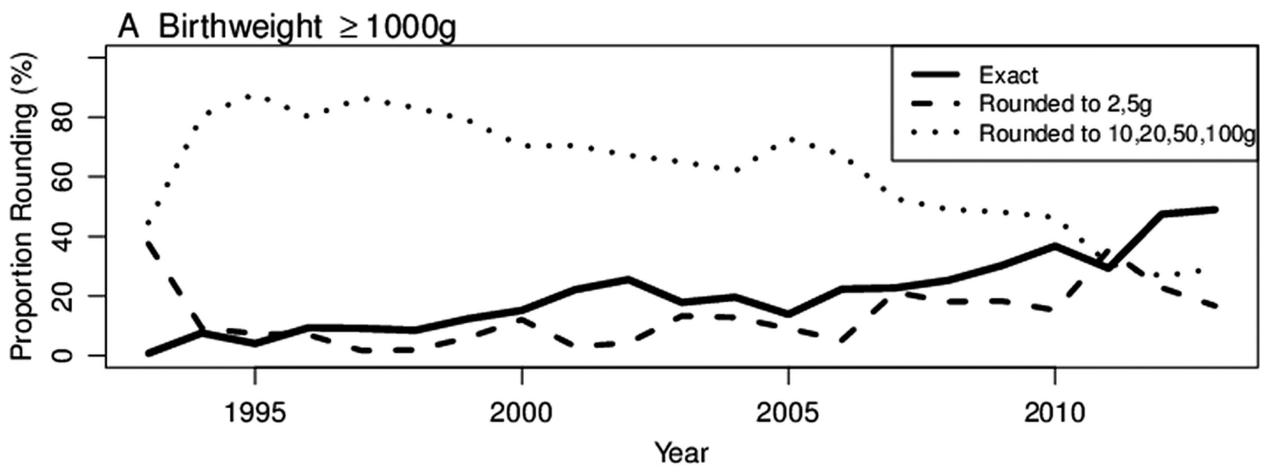

B Birthweight $<1000 \mathrm{~g}$

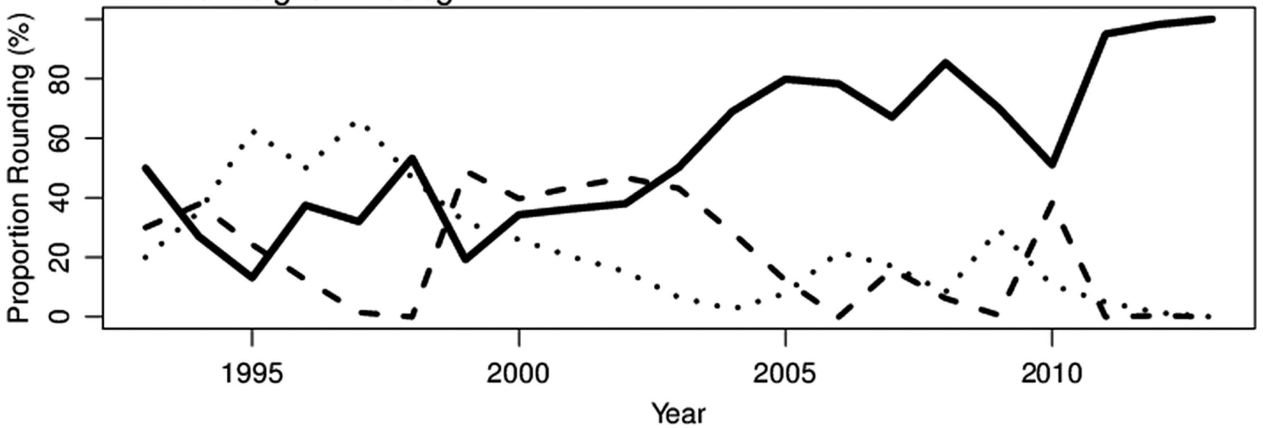

Figure 3 Change in accuracy over time: modelled proportions recorded exactly, rounded by a small amount (to nearest 2 or $5 \mathrm{~g}$ ) or a larger amount (to nearest $10,20,50$ or $100 \mathrm{~g}$ ).

infants admitted to NICU, most infant drug doses are administered based on weight criteria. For infant safety, it is important to ensure accuracy of calculated doses by using reliable weight measurements. A long-standing nursing protocol has required deduction of the weight of any extraneous item not able to be removed at the time of weighing after birth. It was surprising therefore to find that our data showed that for infants $<1000 \mathrm{~g}$, $4.5 \%$ had their birth weights rounded to the $50 \mathrm{~g}$ level and $23.5 \%$ had rounding by $10 \mathrm{~g}$ or more. For infants $\geq 1000 \mathrm{~g}$, more of the weights were rounded with $61.1 \%$ rounded by $10 \mathrm{~g}$ or more, however, the overall error level was nevertheless lower. The data also showed that there was improvement in accuracy over time with a lower proportion showing digit bias.

Many drug errors are due to poor manual calculation and there is evidence that the use of computerised prescribing can reduce errors significantly. ${ }^{9}$ All neonatal prescribing software packages rely on the accuracy of the measured weight. The need for precise birth weight measurements may not be fully appreciated by those undertaking weighing, but the reason for digit bias leading to rounding or truncation of the absolute measured weight remains unclear. The strength of this study is the large number of infants who were able to be analysed even at $<1000 \mathrm{~g}$. The data were entered contemporaneously and were all used for prescribing throughout the study period, so the importance of accurate data entry was clear. One weakness is that, due to the retrospective nature of the study, it is not possible to explore with staff the reasoning for rounding or truncating the measurements. There are, to our knowledge, no other studies of a similar population over a prolonged period.

The formal analysis of the data was based on the assumption that there would be an equal number of birth weights in each digit weight group. Given that the range of weights $(500-4500 \mathrm{~kg})$ is much greater than the putative digit preferences $(0-100 \mathrm{~g})$, this is a reasonable approximation and only small biases in digit frequencies can be accounted for by the non-uniform distribution of birth weights, unlike the situation in other digit preference studies, for example, age. ${ }^{8}$

The difference between rounding and truncation in very small infants compared with the infants $\geq 1000 \mathrm{~g}$ suggests that there is a modification in the nurses' behavioural response to the measured weight and an understanding that rounding or truncation may influence the outcome to a greater degree in the very small infants (figure 2). It is interesting to note that there was also a reduced incidence of digit bias in infants $<1000 \mathrm{~g}$ in the Canadian provincial study from 1981 to $1991 \mathrm{com}-$ pared with those $\geq 1000 \mathrm{~g}^{2}$

It was also considered that part of the reason for digit bias in the Canadian study was the use of analogue scales and that a move to digital scales would provide an automatic increase in accuracy. Our data have been derived solely from digital readout electronic scales and yet there is evidence of digit bias and significant rounding in a significant number of cases.

It is clear from the current study that for both groups of infants there has been an improvement in accuracy of 
recording the birth weight and that this has been greater for those $<1000 \mathrm{~g}$ than those $\geq 1000 \mathrm{~g}$. This is likely to be due to progressive improvements in nurse training and to some degree the greater involvement by nurses in dose checking and non-medical prescribing ${ }^{10}$ over the last decade increasing their understanding of the importance of the accuracy of weight in drug dose calculation. ${ }^{9}$ The absence of any step change in this reflects a steady group behavioural change with increasing attention to accurate weight measurement. There are no comparable data within the literature.

While it is clear that rounding or truncation occurs, our data show that the likely maximum error in the recorded birth weight was $5 \%$ for infants $\geq 1000 \mathrm{~g}$. For infants $<1000 \mathrm{~g}$, the maximum digit bias was $50 \mathrm{~g}$ rather than $100 \mathrm{~g}$ which again gives a maximum $5 \%$ recorded weight error. However, the maximum error from rounding birth weights is within the published recommended rounding tolerances. ${ }^{11}$ Thus, this degree of error in birth weights, even for the smallest of infants, is tolerable.

Acknowledgements The authors would like to thank the neonatal nurses who weighed the infants at birth and the junior doctors who entered the birth weights onto the electronic patient record.

Contributors AJE conceived of the study, extracted the data and wrote the paper; SAR provided statistical analysis, reviewed and contributed to the final draft

Funding This research received no specific grant from any funding agency in the public, commercial or not-for-profit sectors.

Competing interests None.

Ethics approval The use of data from the database was approved by the NHS Research Ethics Committee (Haydock) 13/NW/0159.
Provenance and peer review Not commissioned; externally peer reviewed.

Data sharing statement No additional data are available.

Open Access This is an Open Access article distributed in accordance with the Creative Commons Attribution Non Commercial (CC BY-NC 3.0) license, which permits others to distribute, remix, adapt, build upon this work noncommercially, and license their derivative works on different terms, provided the original work is properly cited and the use is non-commercial. See: http:// creativecommons.org/licenses/by-nc/3.0/

\section{REFERENCES}

1. The Institute of Medicine. Preventing medication errors. Washington, DC: The National Academies Press, 2006. http://www.iom.edu/Reports/ 2006/Preventing-Medication-Errors-Quality-Chasm-Series.aspx

2. Safety in doses: medication safety incidents in the NHS: the fourth report from the Patient Safety Observatory. http://www.nrls.npsa.nhs.uk/ EasySiteWeb/getresource.axd?AssetID=61392 (accessed Apr 2013).

3. Reducing prescribing errors: evidence scan. The Health Foundation http://www.health.org.uk/publications/reducing-prescribing-errors/ (accessed Apr 2013)

4. Franklin BD, Reynolds M, Shebl NA, et al. Prescribing errors in hospital inpatients: a three-centre study of their prevalence, types and causes. Postgrad Med J 2011;87:739-45.

5. Safer use of intravenous Gentamicin for neonates/Gentamicin Alert| 2010-02-03l. http://www.nrls.npsa.nhs.uk/alerts/?entryid45=66271 (accessed Apr 2013).

6. Thavarajah S, White WB, Mansoor GA. Terminal digit bias in a specialty hypertension faculty practice. J Hum Hypertens 2003;17:819-22.

7. Edouard L, Senthilselvan A. Observer error and birthweight: digit preference in recording. Public Health 1997;11:77-9.

8. Camarda CG, Eilers PHC, Gampe J. Modelling general patterns of digit preference. Stat Model 2008;8:385-401.

9. Jozefczyk KG, Kennedy WK, Lin MJ, et al. Computerized prescriber order entry and opportunities for medication errors: comparison to tradition paper-based order entry. J Pharm Pract 2013;26:434-7.

10. McCann L, Haughey S, Parsons C, et al. Pharmacist prescribing in Northern Ireland: a quantitative assessment. Int $J$ Clin Pharm 2011;33:824-31.

11. Johnson KB, Lee CKK, Spooner A, et al. Automated dose-rounding recommendations for pediatric medications. Pediatrics 2011;128:e422. 